\title{
Empirical Study on Green Design Transformation of the Old Industrial Buildings
}

\author{
Junmei Li \\ CHINA AVIATION PLANNING AND DESIGN INSTITUTE CO.LTD,Beijing100120,China
}

hunter2011@foxmail.com

Keywords:Old Industrial Building; Green Transformation; Energy Saving.

\begin{abstract}
With the development of China' s social and economic, as well as in a high speed urbanization and rapid city stages of development, the construction industry have become an important pillar industry in China, and the existence of the old building intensive, through green design standards in order to achieve sustainable development. In this paper, we take office building of Suzhou Institute of Architectural Design as the case, to explore the green design transformation of old industrial buildings.
\end{abstract}

\section{Significance of the Green Transformation of Old Industrial Buildings}

For the old industrial buildings of a long service life, its transformation must take the resource conservation development model. The transformation process of old industrial buildings requires a combination of ecological philosophy, so as to realize resource saving, environment protecting and cultural heritage.

(1) Social resources saving

If demolish the old industrial buildings that still have use value, it will inevitably result in a waste of resources. Similarly, irrational transformation will also result in a waste of social resources. Energy saving design of external maintenance structure, natural daylight, and natural ventilation should be considered in transformation process. Any ecological improvement measures would can reduce or avoid the emergence of energy waste and environmental pollution problems brought about by traditional transformation.

(2) Environment protection

In the demolition process of old buildings, it would consume considerable human, financial and material resources, and meanwhile generate a lot of construction debris and dust, leading environmental pollution. Reconstruction would also occupy a large number of new resources, and cause secondary pollution.

If designers do not consider environmental factors inside and outside the building at planning, design, construction, and operation phases, the surrounding environments is possible to be polluted. For green design transformation, it not only needs to focus on the overall objectives that inside and outside environment of the entire building become healthy and sustainable, but also should pay more attention to the ecological environment of the entire building life cycle, rather than one aspect or one period.

(3) Historical culture heritage

Since old industrial buildings had been some time in the region, and formed relatively mature social resources, so in order to avoid the loss of history and culture, people should not carry out large-scale demolition. After transformation with green ecological idea, inheritance of historical context is guaranteed, and is integrated into an organic and continuous development process.

\section{Case Study of Green Design Transformation Project}

Overview. Here we take office building of Suzhou Institute of Architectural Design as the case. This project is located in Suzhou Industrial Park, with total construction area of 12,673 square meters. Before transformation, it was America West Airlines Factory, but its functional orientation shifted into supporting business service area after removal. Demolition and reconstruction will 
cause a huge waste, so government hope to transform the original building to extend its life and optimize the use of resources. Meanwhile, sustainable development of architecture should be considered in design, and integrate health humane green elements, to create ecologically sustainable and comfortable living environment, as shown in Fig. 1:

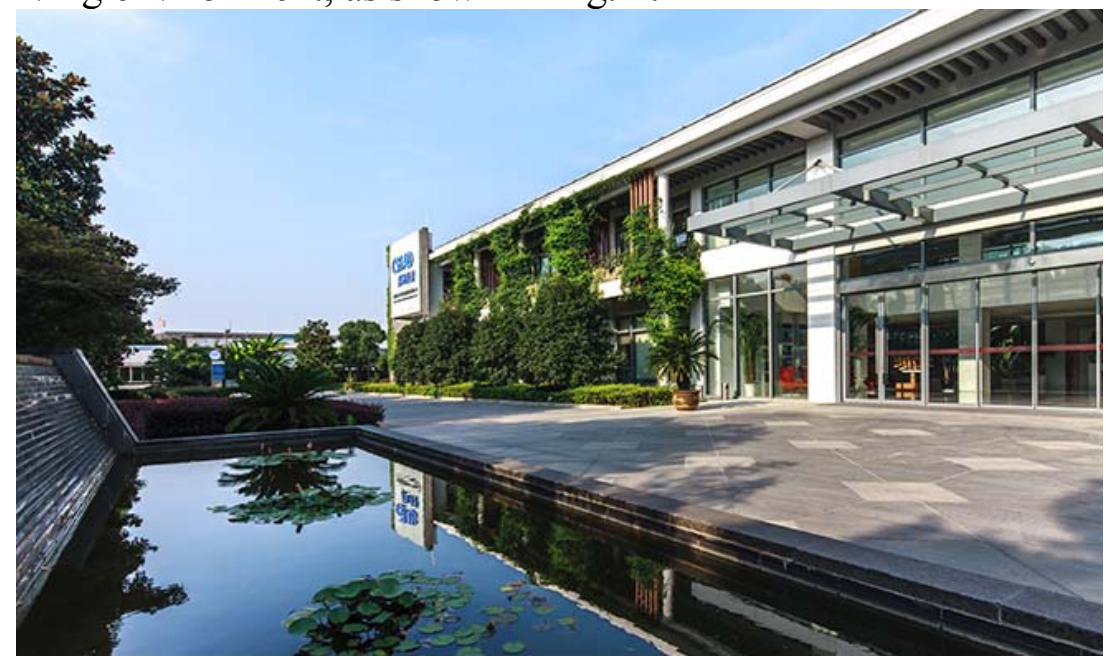

Fig. 1. Transformation effect

Targets. Every success project has a clear goal. For green transformation of old industrial buildings, should develop scientific and reasonable improvement goals combined with the actual situation. In the green transformation of office building of Suzhou Institute of Architectural Design, the design targets are as follow:

a) Build new office space, and the working environment that can stimulate creative inspiration and adapt to design concept.

b) Respect regional cultures, and based on current old industry architectural structure, combine local traditional elements and fashion elements.

c) Apply green building technologies, and make efforts to build a successful sustainable green office building.

Transformation Techniques. Under the idea of ecological green building design, this project fully combines the structure of old industrial architecture and the regional climate and conditions in Suzhou. According to the regional characteristics in Suzhou, designers worked out a suitable strategy for transformation, that is, on the basis of environment protecting, introduce natural ventilation and natural lighting into the building, so that reduce resource consumption with less economic investment.

(1) Structural transformation

Before transformation, the original workshop is single layer concrete frame structure. The transformation design retained $95 \%$ main structure of the old workshop, and through structure security detection, reinforced the original structure before use.

(2) Functional transformation

In transformation design, the original $8.4 \mathrm{~m}$ single-level industrial plant was redesigned as a $14 \mathrm{~m}$ multilayer office building. Its internal functions not only included offices, conference rooms, and studio, but also restaurant and entertainment function space provided for staff. Thus, the old factory with total construction area of $6800 \mathrm{~m}^{2}$ has become a $12763 \mathrm{~m}^{2}$ green ecological creative office space, as shown in Fig. 2: 


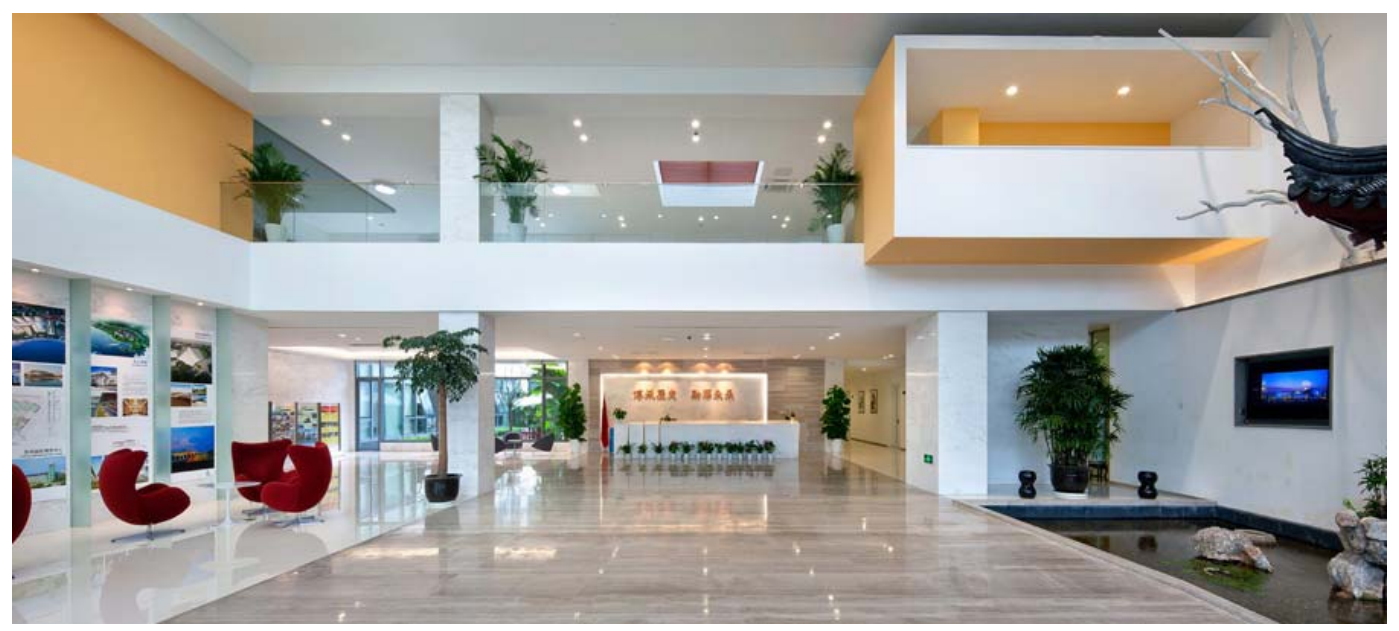

Fig. 2. Functional space transformation

(3) Retaining wall transformation

a) Outer fence. Set green corridor outside the building as resting space. The top of the platform was made of aluminum alloy, and its outside was erected with jardinière planting deciduous plants. The plants flourished to grow in summer, becoming natural green shade barriers; in winter, foliage of plants decay and fall down, so does not affect demand for winter lighting. In addition, designers arranged removable strip planting groove for outside landscape in south balcony.

For outer fence color transformation, the main color was originated from unique traditional color of Suzhou - gray. Gray paint has a high reflectivity, so it can reduce the heat radiation effect under hot weather conditions. Meanwhile, designers adopted internal heat insulation design with self-heat preservation wall material, to reduce indoor energy consumption.

b) Roof transformation. Firstly, reinforce the roof of the old factory. In order to make full use of solar energy, the original skylights were redesigned, and with efficient light pipe and transparent cover with UV filtering function, introduce the sunshine into the building, so that the working space, stairs, corridors and halls could share the natural lighting.

(4) Spatial transformation

a) Building space. Old industrial buildings can optimize its internal functional properties by certain architectural design techniques. Through certain processing such as layers adding or inner courtyard excavation, the originally drab building space would become vivid, and make use of relevant green technology design means to achieve green building projects. After transformation, the two-high foyer space was divided into two parts: the first layer is a support services and office space area; the second layer is Creation Center and other design departments. Such arrangements helped to reduce the communication streamline in daily work and effectively promote the working efficiency.

b) Internal natural ventilation. By computer simulation analysis, the large windows were arranged on the periphery of the building, to introduce the natural wind into the building interior space. After the implementation of the design scheme, the indoor temperature of the new building space was reduced by $2{ }^{\circ} \mathrm{C}-3^{\circ} \mathrm{C}$, and air conditioning using time decreased by 160 hours.
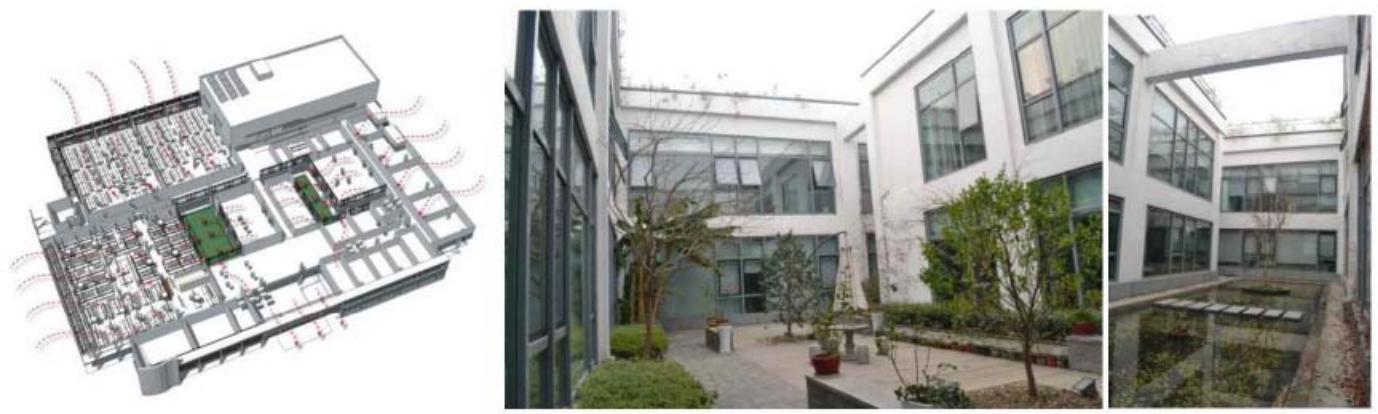

Fig. 3. Natural ventilation design and the inner courtyard 
c) Indoor design. In the early stage of architectural design, we should consider the choice of energy saving materials and energy saving measures implementation, so it needs to communicate and coordinate with equipment and indoor experts. According to the principles of green, environmental protection and sustainable use, building walls used anion water putty, which has good moisture-proof and insulation effect; the ground was coated with environmental linen material made from renewable natural materials, because this material is easy to clean and recyclable.

d) Site landscape design. This project took full advantage of the existing plant roads, and conducted green design on surrounding site landscape, as well as retained the traditional features. Tall trees were planted around the building, and design of step shaped green belt played a very good role in noise reduction. There was an artificial slope in the west side of the building, with many large evergreen plants, so as to cover the northwest wind in winter.

Green Technologies Application. (1) Rainwater reuse system. The old industrial building had a perfect municipal water supply system, so it was directly connected to the municipal water supply pipe network. Original drainage pipes were retained in the transformation. By design of rainwater harvesting system, rain water on the roof and the ground can be collected and reused, and domestic sewage can be purified as well. The reused rainwater and sewage was used for watering, washing and flushing.

(2) Electrical energy-saving systems. Electrical energy-saving systems belong to active energy saving technologies. Because of original industrial production demands, the old industrial building was equipped with water supply, power supply equipment. Considering the use value of existing equipment, designers just re-planed the electricity load, but retained the equipment. In addition, for air conditioning, lighting, office equipment and hot water and other major energy consumption equipment, installed sub metering remote transmission devices, and then detected the consumption by data software, so that people can timely adjust energy use.

(3) HVAC system. Passive energy saving technology can't create a totally suitable environment, so the use of air condition is necessary. According to incomplete statistics, air conditioning energy consumption accounts for about $50 \%$ of the annual energy consumption of buildings, so energy consumption of HVAC system is the focus of green transformation. In this project, designers adopted a modern simulation technology - CDF, and installed full heat exchange air breathing machine, which could recycle the energy contained in indoor ventilation. These measures above can save energy consumption of $10 \%-15 \%$.

\section{References}

[1] Y.Y. Chen. Economic Values of the Transformation of Old Industrial Buildings in Modern Cities. Journal of Wuhu Vocational Institute of Technology, 2006.

[2] H. Xu. The Reservation and Transformation of Industrial Buildings in Industrial Wasteland Update. Friend of Science Amateurs, 2011.

[3] F.Q. Yin, H.M. Li. The Current Situation of the Reuse of Architectural Transformation of the Old Industrial and Advice. Advanced Materials Research, 2014, 869-870:130-133.

[4] Z. Shi. Continuation of the place spirit in the process of transformation of old industrial buildings. Shanxi Architecture, 2013.

[5] Y. Sun. Handling Techniques of Interior Wall in the Old Industrial Buildings Transformation. Value Engineering, 2010.

[6] W.U. Bo. Transformation of the Old Factory Buildings, Industrial Heritage. Art \& Design, 2009. 